\title{
THE ROLE OF BENEFITS IN ATTRACTING, RETAINING AND MOTIVING PERSONNEL
}

\author{
(C) 2020 Grishina Valeria Alexandrovna \\ Student \\ (C) 2020 Zarodina Alina Vadimovna \\ Student \\ Samara State University of Economics \\ E-mail: scorpiony70@mail.ru
}

Keywords: staff attraction, staff retention, staff motivation, benefits, state benefits, organization benefits for employees, personnel, staff satisfaction, social protection, social assistance, incentive.

The article analyzes the characteristic features of the process of attracting, retaining and motivating personnel, considers the functions of attracting, retaining and motivating personnel from the perspective of the object and subject of management, analyzes the classification of incentives used in the organization for employees, describes the classification and specific features of various benefits used in organizations for staff. The benefits in the federal network of Japanese cuisine "Sushishop" are considered.

УДК 336.

Код РИНЦ 06.00.00

\section{СУЩНОСТЬ И ПРИНЦИПЫ БАНКОВСКОГО ПОТРЕБИТЕЛЬСКОГО КРЕДИТОВАНИЯ}

\author{
(C) 2020 Гусарова Дарья Дмитриевна \\ магистрант \\ (C) 2020 Вишневер Вадим Яковлевич \\ кандидат экономических наук, доцент \\ Самарский государственный экономический университет \\ E-mail: ab3535@mail.ru
}

Ключевые слова: банковский потребительский кредит, заемщик, кредитор, принципы банковского потребительского кредитования, коммерческий банк.

В статье рассмотрена сущность банковского потребительского кредита. Выявлены основные принципы банковского потребительского кредитования.

Современные нестабильные экономические условия поставили перед российским банковским сектором новые задачи в развитии рынка потребительского кредитования. Исследование накопленных в период кредитной экспансии рисков, высокого уровня просроченной задолженности по потребительским кредитам становится все более актуальным в связи с восстановлением роста данного сегмента финнансового рынка'. 
Снижение инфрляции и процентных ставок по потребительским кредитам способствует стабилизации объемов кредитования фризических лиц. В стратегических планах коммерческих банков предусмотрен дальнейший рост предложений кредитных продуктов населению, что усиливает конкуренцию в банковском секторе и делает потребительские кредиты более доступными для населения.

Вместе с тем, чрезмерная приверженность участников рынка к высокорисковым операциям потребительского кредитования может стать

причиной снижения финансовой устойчивости и банкротства коммерческих банков. Поэтому Банк России становится все более требовательным к участникам рынка потребительского кредитования, оценке рисков кредитования фризических лиц, а также созданию резервов ${ }^{2}$.

Кредитные операции для банков являются основным источником доходов. Поэтому банки наращивают объемы потребительского кредитования. В то же время для многих граждан, не имеющих накоплений, кредиты становятся единственным финансовым источником приобретения жилья, покупки автомобиля и осуществления текущих расходов. Однако, с ростом кредитных портфелей и объемов ссудной задолженности банков возрастают также риски и издержки кредитования.

В законе РФ "О потребительском кредите (займе)" раскрыты основные характеристики потребительского кредита, согласно которым:

- кредит предоставляется на цели, не связанные с предпринимательской деятельностью;

- кредитором выступают организации, осуществляющие профрессиональную деятельность в сфрере потребительского кредитования;

- заемщиками являются граждане, получающие или получившие кредит на конечное потребление;

- кредитные отношения между кредитором и заемщиком оформляются кредитным договором или договором займа;

- объектом кредитных отношений выступают денежные средства, в том числе могут использоваться электронные средства платежа.

К потребительским кредитам в Российской Федерации относят различные виды кредитов, которые предоставляются населению на покупку товаров длительного пользования и первой необходимости, оплату образовательных и медицинских услуг, а также любые виды кредитов на цели конечного потребления 3 .

В связи с тем, что субъектами потребительского кредита являются физические лица, это определяет особые взаимоотношения кредитора с заемщиками, что обусловлено психологическими, социальными и другими особенностями физических лиц, которые не всегда имеют достаточную финансовую грамотность для оценки экономической целесообразности и финансовых возможностей. По этим и другим причинам потребительское кредитование является наиболее рискованным.

Ухудшение состояния здоровья, нестабильность работы и доходов заемщика, изменения в составе семьи и другие факторы оказывают влияние на возврат кредита.

Специфика потребительского кредита проявляется также в методах оценки кредитоспособности заемщиков, которые принципиально отличаются от методов, применяемых для анализа кредитоспособности юридических лиц4 ${ }^{4}$. 
На развитие рынка потребительского кредитования помимо макроэкономической ситуации, состояния банковского сектора в стране и законодательной базы, оказывают влияние демографрические фракторы. Как следствие динамика потребительского кредитования зависит от численности населения по регионам. На объемы кредитования оказывают влияние образование и сфера деятельности граждан, структура экономики и географическое расположение субъекта экономики. Наиболее склонны к потребительскому кредитованию молодые люди, с высшим образованием, имеющих стабильную занятость. Лица старшего возраста или со средним образованием пользуются кредитами в меньшей степени.

Немаловажное значение для раскрытия сущности предоставляемых потребительских кредитов имеют принципы кредитования. Принципы определяют базовые основы, начало, подходы, в рамках которых формируются кредитные отношения с физическими лицами. Принципы могут носить экономический, социальный и другие аспекты кредитных отношений.

Под принципами потребительского кредитования понимают особые правила, формируемые в сфрере кредитования физических лиц. Большинство экономистов в качестве основных принципов кредитования рассматривают:

- возвратность, как основное свойство любого кредита, отличающего его от других экономических категорий;

- платность, поскольку кредитор осуществляет свою деятельность на коммерческой основе;

- срочность.

Кроме того, анализируются такие принципы, как целевое использование, диффееренцированность, обеспеченность, которые в практике потребительского кредитования не являются обязательными. В условиях экономической нестабильности повышается значение принципов добросовестности, ответственности, финансовой подготовленности, рационального использования кредита, финансовой необходимости, ответственности и другие экономические и социальные принципы.

Возвратность является главным принципом кредитования, что обусловлено сущностью кредита как экономической категории. Возвратность обеспечивает выполнения закона сохранения ссуженной стоимости и означает, что средства, предоставленные кредитором заемщику, должны возвращаться в установленные сроки и в полном объеме.

Экономисты отмечают, что принципы кредитования обеспечивают единство и взаимосвязь всех элементов системы кредитования коммерческими банками.

Экономической основой кредита является участие денежных средств в кругообороте и обязательный их возврат к установленному сроку. Временный характер предоставления кредита, его использование в установленные сроки и возвратность отличает кредит от других экономических категорий в сфрере денежно-кредитных отношений. При этом кредит, предоставляемый кредитором, является его собственностью, передается от имени банка на условиях платности, срочности и возвратности. Данные условия являются принципиальными для функционирования кредита. Владелец покрывает временный десицит в денежных средствах и является временным владельцем кредита.

Возвратность имеет существенное значение для кредитора и заемщика, поэтому носит двусторонний характер. Кредитор, предоставляя кредит, предполагает возврат кредита и последующее его использование в обороте. Заемщик при получении кредита 
удовлетворяет временные потребности в денежных средствах, извлекает финансовую пользу, покрывая расходы. В то же время принимает обязательства по своевременному возврату кредита и уплаты процентов.

Возвратность кредита во многом зависит от действий кредитора, который является организатором кредитного процесса, выбирает сферы кредитования, способы предоставления и возврата кредитов. Поэтому условия кредитной сделки должны основываться на принципе возвратности.

Возврат кредита в строго определенный срок является требованием, соответствующим принципу срочности. Данный принцип обеспечивает достижение цели возвратности. Срок кредитования, установленный по кредитному договору, определяет предельное время, в течение которого кредит находится у заемщика - фризического лица.

Соблюдение принципа срочности имеет особое значение, обеспечивает дисциплину и ответственное финансовое отношение к долговым обязательствам. Данный принцип тесно связан с состоянием ликвидности коммерческого банка и влияет на состояние его финанасовой устойчивости.

Осуществляя деятельность на привлеченных и заемных ресурсах, банки обязаны обеспечить их размещение на возвратной основе. Принцип срочности позволяет банку своевременно выполнять обязательства перед вкладчиками и кредиторами.

Соблюдение в совокупности принципов срочности и возвратности способствует снижению просроченной задолженности, уменьшает кредитный риск и размеры создаваемых резервов банков.

Просроченная задолженность для заемщиков означает повышение расходов на уплату повышенных процентов, что отрицательно сказывается на их финансовом состоянии.

Принцип дифрференцированности означает, что банки подходят к решению вопроса о выдаче кредита фризическим лицам на индивидуальной основе. В первую очередь предоставляются кредиты тем заемщикам, которые имеют высокую платежеспособность и в состоянии своевременно вернуть кредит и оплатить проценты. Поэтому банки уделяют большое значение оценке кредитоспособности физического лица, прогнозированию его финансового состояния. Предварительная работа с заемщиком способствует снижению кредитного риска и обеспечению своевременного возврата кредита заемщиком.

Принцип обеспеченности кредита также используется при кредитовании фризических лиц. Следует отметить, что потребительские кредиты предоставляются как с обеспечением, так и без обеспечения. Недвижимость, имущество, ценности, имеющиеся у заемщика, являются вторичными источниками погашения кредита и позволяют банку повысить гарантии возврата ссуды.

При кредитовании физических лиц активно используется такое обеспечение как страхование, поручительство одного или нескольких лиц, гарантии, а также другие обязательства, в принятых законодательством и банковской практикой фрормах.

Принятый в обеспечение залог проверяется кредитором С позиции ликвидности, т.е. способности быстро превращаться в денежные средства для обеспечения возвратности кредита в срок и используется банком-кредитором в качестве покрытия задолженности по процентам, основному долгу, а также издержек по реализации.

Одним из основных принципов в коммерческой деятельности банков является принцип платности, который имеет существенное значение для формирования доходов 
банка. Процент по банковскому кредиту физических лиц является платой за временное использование заемщиком ресурсов коммерческого банка.

Размер кредитной процентной ставки зависит от различных факторов: размера кредита, срока кредитования, риска кредитования заемщика, уровня инфляции, ключевой ставки Банка России, конъюнктуры денежного рынка и др.

Таким образом, принципы банковского потребительского кредитования создают основу формирования эффективных кредитных отношений кредитора и заемщика, способствует раскрытию сущности, видов и форм кредитования физических лиц 5 .

1 Гусарова Д.Д., Вишневер В.Я.Классификация форм и видов банковского потребительского кредитования. // Актуальные аспекты развития современной науки : сб. науч. ст. Междунар. науч. конф., 19 дек. 2019 г. / [редкол.: С.И. Ашмарина, А.В. Павлова (отв. ред.) и др.]. - Самара : Изд-во Самар. гос. экон. ун-та, 2019. - С. 53-58.

2 Вишневер В.Я. Влияние политики мегарегулятора на конкурентоспособность российских банков в ссрере потребительского кредитования. // Российская наука: актуальные исследования и разработки: сб. науч. ст. VIII Всерос. науч.-практ. конф., 10 окт. 2019 г. : в 2 ч. / [редкол.: С.И. Ашмарина, А.В. Павлова (отв. ред.) и др.]. - Ч. 2. - Самара : Изд-во Самар. гос. экон. ун-та, 2019. C. $10-12$.

3 Ващекина, И.В. Классификация потребительских кредитов на российском рынке // Вестник РЭУ им. Г.В. Плеханова. - 2017. - № 3 (93). - С. 45-46;

${ }_{4}^{4}$ Агафонова В.В., Вишневер В.Я., Фрумусаки С.В. Технологическая эволюция кредитного скоринга в системе банковского потребительского кредитования. // Вестник Волжского университета им. В.Н. Татищева, 2018. Т.2., №3. С. 21-26.

${ }^{5}$ Вишневер В.Я., Чаплыгина А.А. Совершенствование системы банковского потребительского кредитования в современной экономике России // Вестник молодых ученых СГЭУ, №1(39), 2018. C. $37-38$.

\title{
ESSENCE AND PRINCIPLES OF BANKING CONSUMER LOAN
}

\author{
(C) 2020 Gusarova Darya Dmitrievna \\ Undergraduate \\ (C) 2020 Vishnever Vadim Yakovlevich \\ Candidate of Economics, Associate Professor \\ Samara State University of Economics \\ E-mail: ab3535@mail.ru
}

Keywords: bank consumer credit, borrower, lender, principles of bank consumer lending, commercial bank.

The article considers the essence of bank consumer credit. The basic principles of consumer banking lending are identified. 